\title{
Mechanical Behavior of the ATLAS B0 Model Coil
}

\author{
A. Foussat, N. Dolgetta, E. Acerbi, F. Alessandria, R. Berthier, F. Broggi, A. Dael, A. Dudarev, C. Mayri, P. Miele, \\ M. Reytier, L. Rossi, M. Sorbi, Z. Sun, H. H. J. Ten Kate, I. Vanenkov, and G. Volpini
}

\begin{abstract}
The ATLAS B0 model coil has been developed and constructed to verify the design parameters and the manufacture techniques of the Barrel Toroid coils (BT) that are under construction for the ATLAS Detector. Essential for successful operation is the mechanical behavior of the superconducting coil and its support structure. In the ATLAS magnet test facility, a magnetic mirror is used to reproduce in the model coil the electromagnetic forces of the BT coils when assembled in the final Barrel Toroid magnet system. The model coil is extensively equipped with mechanical instrumentation to monitor stresses and force levels as well as contraction during a cooling down and excitation up to nominal current. The installed set up of strain gauges, position sensors and capacitive force transducers is presented. Moreover the first mechanical results in terms of expected main stress, strain and deformation values are presented based on detailed mechanical analysis of the design.
\end{abstract}

Index Terms-ATLAS magnet, capacitive force transducers, strain gauges, stress measurements, toroidal coil.

\section{INTRODUCTION}

HE ATLAS Magnet System [1], which consists of 8 Barrel Toroid (BT) coils, 2 End Cap Toroids (ECT) and the central solenoid, is one of the largest superconducting magnet system built so far with total energy of 1.5 GJ. One BT coil is $26 \mathrm{~m}$ long and $5 \mathrm{~m}$ wide. During operation of the ATLAS detector, each BT coil undergoes large radial electromagnetic centering forces which are reacted by warm structure via tie rod system. The short B0 toroid model coil $(9 \mathrm{~m} \times 5 \mathrm{~m})$ has been designed and fabricated by CEA Saclay and INFN/LASA to verify the mechanical operating behavior and validate some design parameters of BT. The test station including cryoplant, power supplies, magnetic mirror, monitoring and safety systems were set up at CERN [2] while the data acquisition systems were integrated in collaboration between the institutes and CERN. The use of the magnetic mirror reproduces the external EM forces level during power test to validate mechanical construction.

To validate the mechanical behavior, the model coil has been extensively equipped with strain gauges, capacitive force transducers and position sensors. Some mechanical design choices are presented as well as the instrumentation layout. The predictions on the mechanical behavior of the $\mathrm{B} 0$ coil are presented as

Manuscript received September 24, 2001.

A. Foussat, A. Dudarev, P. Miele, L. Rossi, H. H. J. Ten Kate, and I. Vanenkov are with CERN, Geneva, 1211 Geneva 23, Switzerland.

R. Berthier, A. Dael, C. Mayri, M. Reytier, and Z. Sun are with CEA/DSM/DAPNIA 91191 Gif sur Yvette Cedex, France.

N. Dolgetta is with Euratom- CEA CADARACHE 13108 St. Paul lez durance Cedex, France.

E. Acerbi, F. Alessandria, F. Broggi, M. Sorbi, and G. Volpini are with

LASA/INFN via F.lli Cervi, 201 - 20090 Segrate Milano, Italy.

Publisher Item Identifier S 1051-8223(02)03567-4.

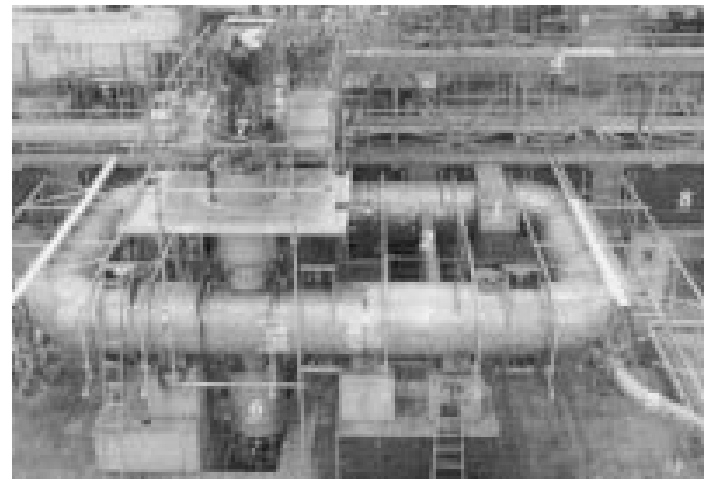

Fig. 1. Layout of B0 coil testbench: (1) Support units, (2) ribs, (3) vacuum vessel, (4) busbars system, (5) vacuum line, (6) cryogenic service turret, (7) current lead turret, (8) magnetic mirror.

well as the results of the first campaign of tests during cooling down and excitation up to $20.5 \mathrm{kA}$.

\section{MEChANICAL DESIGN}

The main mechanical features include the coil casing, the titanium tie rods, the cryogenic stops, the cooling circuit, the thermal shields and the vacuum vessel. The aluminum alloy 5083 casing encloses two NbTi double pancake windings. The casing guarantees cooling, rigidity and transfer of the magnetic forces with limited deformations. Two ribs, welded to the casing, symmetrically placed over the $9 \mathrm{~m}$ length, increase the rigidity. The winding and casing are referred to as the cold mass. The electromagnetic external forces, produced by the magnetic mirror, are reacted by three titanium tie rods, anchored to the casing and the vacuum vessel via pivot mechanisms. The titanium material for the tie rods fulfills both requirements of a light, slim structure, and of high mechanical strength to sustain forces up to 200 Tons at each tie rod. In the test facility, each tie rod head is rigidly connected to the magnetic mirror via massive steel supports (Fig. 2). The thermal shields consist of Al5083 panels supported on the coil through glass epoxy tubes.

The cold mass and thermal screens are supported on the vacuum vessel via 6 glass epoxy supports, named cryogenic stops, which must allow for the displacements of the cold mass during cooling down, warm up and during energization. As these supports constitute a major heat load to the cold mass, they were especially developed, optimizing fiberglass layers of the tubes, to minimize the material thickness and optimize the mechanical strength.

Each cryogenic stop is made of one "cold" stop, anchored to the cold mass on one side and a "warm" stop, anchored to the vacuum vessel; in between a "half sphere," allows for the 


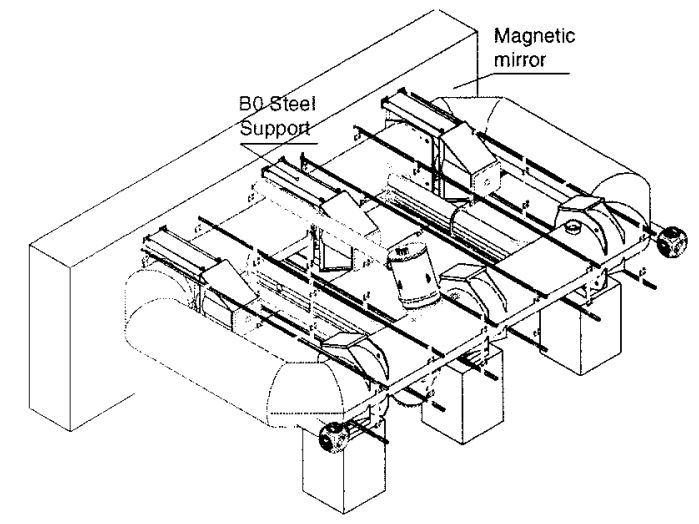

Fig. 2. B0 coil magnetic mirror layout.

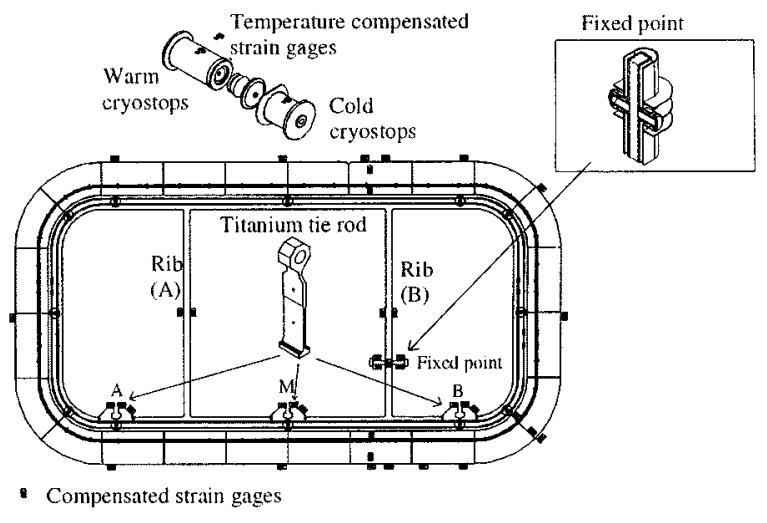

Fig. 3. Positions of strain gauges on B0 coil.

relative sliding of the structure. To avoid shear force in the supports, friction is minimized by mirror polishing of the stainless steel surfaces at the sliding surfaces of the cryogenics stops, and Teflon coating of the half sphere.

\section{INSTRUMENTATION}

The B0 model racetrack coil has a standard mechanical instrumentation based on uniaxial, biaxial and rosette strain gauges in addition with in house developed capacitive force transducers for EM force measurements and displacement transducers to monitor thermal contraction of B0 model. Fig. 3 shows the strain gauges positions ( 89 in total) on different parts of B0 coil.

Position Sensors: Two displacement transducers based on potentiometer are used to monitor the thermal contraction of the coil casing along its long side with respect to the fixed point of the coil.

Strain Gauges: The strain gauges and displacement transducer data acquisition is managed by a Magnet Control System (MCS) based on a Siemens S7400 PLC interfaced with the Labview 6i supervisor program.

The strain gauges data acquisition system consists of a UPM100 acquisition unit interfaced to PC supervisor Labview program. This program performs all settings and alarm value control relevant for strain measurement. Both temperature compensated half bridges and quarter bridges are driven by $600 \mathrm{~Hz}$ frequency carrier excitation $0.5 \mathrm{~V}$ signal for error free operation.
TABLE I

TOROIDAl B0 COIL MAIN PARAMETERS

\begin{tabular}{ll}
\hline \hline Dimensions & $5 \mathrm{~m} \times 9 \mathrm{~m}$ \\
Cable Cross Section & $57 \times 12 \mathrm{~mm}^{2}$ \\
Operating Current & $20.5 \mathrm{kA}$ \\
Stored Energy & $46 \mathrm{MJ}$ \\
Operating Temperature & $4.4 \mathrm{~K}$ \\
Critical Current $(4.2 \mathrm{~K} 5 \mathrm{~T})$ & $47.5 \mathrm{kA}$ \\
Maximum magnetic Field & $4 \mathrm{~T}$ \\
RRR (Al) & $>1000$ \\
Total weight & 40 tons
\end{tabular}

TABLE II

MaIn Mechanical Strain GaUges InStRUMENTATION ON B0 CoIL

\begin{tabular}{|c|c|c|c|c|}
\hline Parts & $\begin{array}{l}\text { Strain gauges } \\
\text { type }\end{array}$ & Qty & $\begin{array}{l}\text { Expecte } \\
\text { levels (1 } \\
\text { (a) } 4.2 \mathrm{~K}\end{array}$ & $\begin{array}{l}\text { Max stress } \\
\mathrm{Pa}) \\
\mathrm{In}=20.5 \mathrm{kA}\end{array}$ \\
\hline $\begin{array}{l}\text { Coil casing } \\
\text { Cryogenics }\end{array}$ & SK $15250 \mathrm{AF} 350^{*}$ & 21 & 12 & 50 \\
\hline Stops & SK $15250 \mathrm{AF} 350$ & 9 & 0 & -45 \\
\hline Ribs & SK 15250 AF 350 & 5 & -50 & 50 \\
\hline Tie rods & SK 15250 WT350 & 14 & $\begin{array}{l}-15 \\
-15\end{array}$ & $\begin{array}{l}350(\mathrm{~A} / \mathrm{B}) \\
400(\mathrm{M})\end{array}$ \\
\hline Tie rods root & tsSK15250RA350 & 27 & -40 & 40 \\
\hline Fixed Point & SK15250AF350 & 4 & & \\
\hline Shields & SK15250AF350 & 9 & 0 & 10 \\
\hline Total & & 89 & & \\
\hline
\end{tabular}

Table II summarizes the group of strain gauges mounted on B0 model coil together with respective predictive stresses.

\section{A. Capacitive Force Transducers}

In order to monitor the EM external forces during excitation of B0 model coil, special configuration capacitive force transducers were developed at CERN [3]. In total, B0 coil was equipped with 18 load cells: 12 transducers were fixed on four feet of each steel support to measure the forces between the coil and the mirror and 6 transducers were installed on the vertical external supports, mostly for a safety reason to monitor a minor vertical components of EM forces. All the transducers were individually calibrated with a precision of $\pm 5 \%$ in the load range 0 $\div 500 \mathrm{kN}$. The sensitivity factor of capacitive force transducers is around $0.34 \mathrm{pF} / \mathrm{kN}$. With the aim to have a more detailed picture on the force distribution between coil supports, some of these transducers were split into three active parts. One extra transducer was used as a temperature-compensating gauge. A multichannel data acquisition system for capacitive gauges is based on a LCR meter (Hewlett Packard 4264A) and an analog multiplexer (Keithley 7001) driven by a Labview program via GPIB interface. A schematic of this system is shown on Fig. 4.

\section{STRESSES IN B0 CoIL}

\section{A. Electromagnetic Forces}

The magnetic field generated by the $\mathrm{B} 0$ coil in the mirror configuration was calculated by a 3-D TOSCA Biot Savart magnetic code. Thereafter, the Electromagnetic forces (EM) on the double 


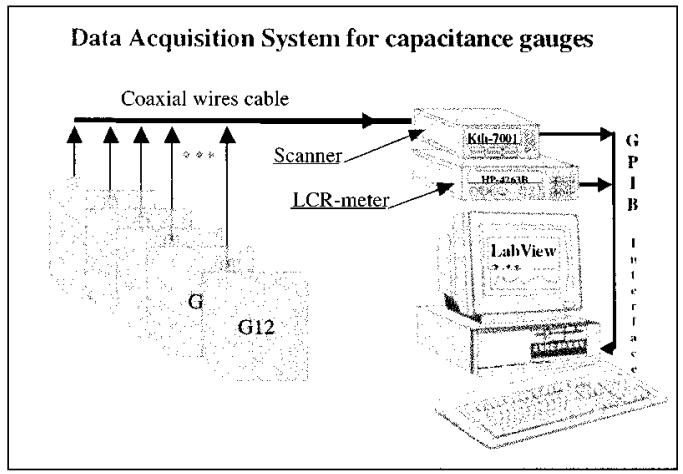

Fig. 4. Layout of capacitive force transducer DAQ system.

TABLE III

FEA EM FORCES CALCULATIONS

\begin{tabular}{ll}
\hline \hline Mean magnetic force on coil & $420 \mathrm{kN} / \mathrm{m}$ \\
Mean magnetic force on & \\
straight length near mirror & $950 \mathrm{kN} / \mathrm{m}$ \\
EM Tensile force in Ribs & $1080 \mathrm{kN}$ \\
Resultant EM radial force & $3700 \mathrm{kN}+1-10 \%$
\end{tabular}

pancakes were inserted in ANSYS beam model for stress calculations.

Table III shows the resulting EM forces calculated for a distance $d=384 \mathrm{~mm}$ of the conductors edge from the mirror [4], [5], which corresponds to the operational conditions.

\section{B. FEA Stress Model}

Stress distribution in the coil casing has been analyzed using finite element ANSYS ${ }^{\circledR}$ package.

1) Beam Model: The aluminum alloy 5083 coil casing is modeled with beams elements (Fig. 5) with mechanical properties representing the stiffness of cold mass. This model was used in order to calculate the global mechanical stresses and deformations in the toroid coil casing racetrack shape.

\section{Mechanical Measurements}

The strain gauges measurements are compensated for the increase of gauge factor $(g=2.11)$ respectively of $+3 \%$ and $+4 \%$ at $50 \mathrm{~K}$ to $5 \mathrm{~K}$.

\section{A. Cooling Down Phase}

B0 model coil is indirectly cooled down by LHe pipes glued on the coil casing. The layout of cooling pipes was chosen to optimize the temperature margin of superconductor [6]. To avoid any important thermal stresses, cooling down is performed in such a way to control temperature gradients on both coil casing and thermal shields to less than $40 \mathrm{~K}$. It is of utmost importance to check up the mechanical behavior of force transfer systems, like cryogenics stops supports, tie rods and fixed point, during the thermal contraction of the coil.

1) Thermal Contraction: The thermal contraction of the coil is dominated by the Alloy 5083 material properties, which results in a total measured longitudinal thermal contraction of

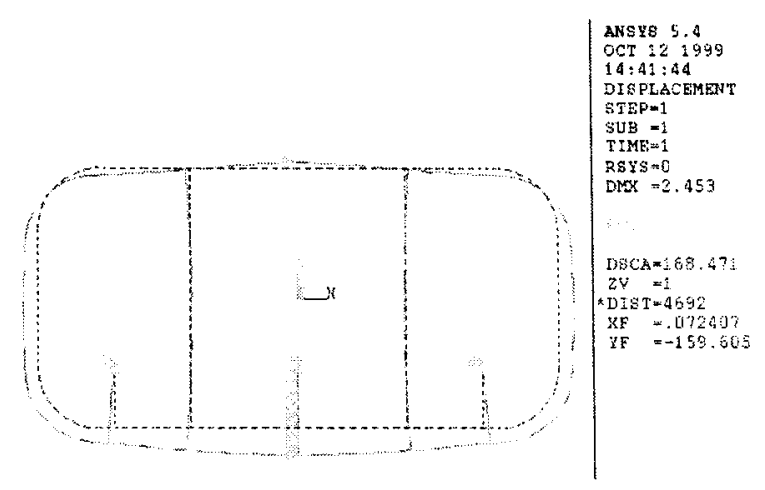

Fig. 5. Beam model of B0 coil deformation.

TABLE IV

DATA USED IN ANALYSES

\begin{tabular}{ll}
\hline Titanium. & $\mathrm{E} 293 \mathrm{~K}=115 \mathrm{GPa}$ \\
& \\
& $\int \alpha \mathrm{K}=131 \mathrm{GPa}$ \\
& $\mathrm{E} 293 \mathrm{~K}=293 \mathrm{~K}=4 \mathrm{~K}=-1.51 \mathrm{GPa} / \mathrm{m}=$ \\
Aluminum alloy & $\mathrm{E} 4 \mathrm{~K}=80 \mathrm{GPa}$ \\
& $\int \alpha \Delta 293 \mathrm{~K}-4 \mathrm{~K}=-4.19 \mathrm{~mm} / \mathrm{m}$ \\
& $\mathrm{E} 293 \mathrm{~K}=200 \mathrm{GPa}$ \\
Stainless Steel & $\mathrm{E} 4 \mathrm{~K}=210 \mathrm{Gpa}$ \\
\hline
\end{tabular}

*" Integrated thermal shrinkage coefficient from $293 \mathrm{~K}$ to $4.2 \mathrm{~K}$.

$37 \mathrm{~mm}$ consistent with the $0.4 \%$ contraction. Asymmetric longitudinal contractions with respect to position the of the fixed point was verified with position sensors.

2) Ribs: As the rib are indirectly cooled by thermal conduction one gets a global structural deformation of the cold mass which results in a tensile stress on the ribs up to $20 \mathrm{Mpa}$.

3) Cryogenics Stops: The thermal contraction of B0 coil induces some stick and slip phenomenon (Fig. 5) at the sliding surface of the cryogenic stops. The measurements show strain levels which are considerable less than the limit value of $1500 \mu \mathrm{m} / \mathrm{m}$, which corresponds to some $30 \mathrm{MPa}$ maximum bending stress.

The total mean bending strain increase per cryogenics stop during cooling down is $-240 \mu \mathrm{m} / \mathrm{m}$, which corresponds to a sliding force of $2.75 \mathrm{kN}$. Considering a maximum loading on cryogenic stop of $47 \mathrm{kN}$, the static friction coefficient is 0.055 .

4) Tie Rods System: A spring washer based system is used to keep minimum compressive forces applied on the tie rods during cooling down, once they reach the median position. The critical buckling load is given by $P c=m \cdot\left(\pi^{2} . E . I\right) / L^{2}=$ $26 \mathrm{Mpa}$ ( $m=1$ if both ends are articulated). The maximum axial compressive strain measured on tie rod A is $-180 \mu \mathrm{m} / \mathrm{m}$ which corresponds to $21 \mathrm{MPa}$ compressive load.

\section{B. Excitation Phase}

A series of current ramps up to $20.5 \mathrm{kA}$ have been performed.

For EM forces analysis, zero point setting of strain gauges indicators was carried out in order to derive the net strain signal induced by Lorenz force. 


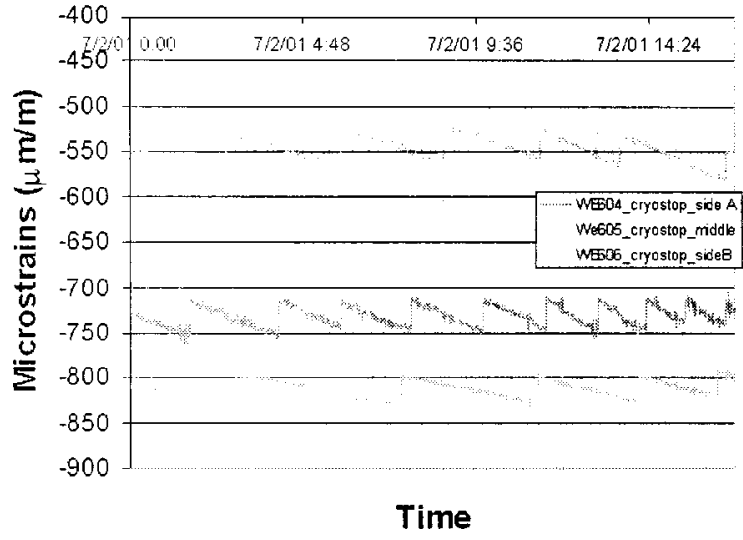

Fig. 6. Mechanical behavior of the cryogenics stops during cooling down.

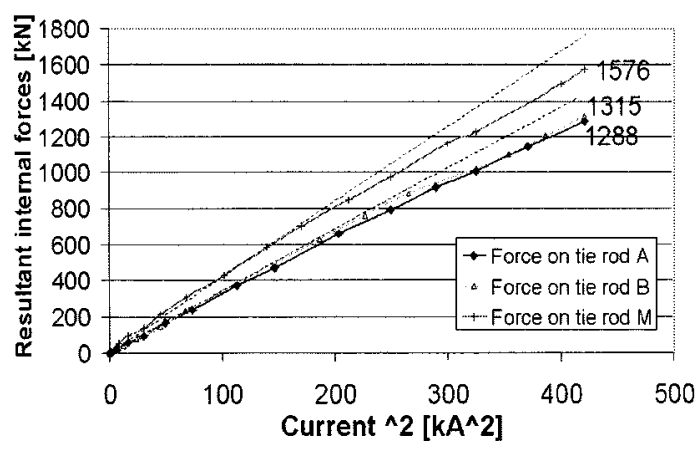

Fig. 7. Radial forces measurement with strain gauges on titanium tie rods.

1) Tie Rods System: Some calibration load proof tests on the tie rods at cold temperatures have been carried out at LASA [7] which result in a titanium E modulus of $118 \pm 2 \mathrm{GPa}$ at $50 \mathrm{~K}$ and $105 \pm 2 \mathrm{GPa}$ at $110 \mathrm{~K}$.

At nominal current $20.5 \mathrm{kA}$, using strain gauges, a net maximum tensile force of $1576 \mathrm{kN}$ was measured on the middle tie rod, $1292 \mathrm{kN}$ on side $\mathrm{A}$, and $1315 \mathrm{kN}$ on side $\mathrm{B}$ which gives a total resultant radial force of $4170 \mathrm{kN} \pm 15 \%$ (see Fig. 7).

This measured total radial EM force is consistent with prediction design from Table III. One notices a nonlinear effect on forces beyond $12 \mathrm{kA}$, which could be due to magnetic mirror saturation effect and internal/external redistribution of forces.

The radial forces against the magnetic mirror measured with capacitive force transducers are reported in Fig. 8 giving a maximum EM radial force of $4575 \mathrm{kN} \pm 5 \%$.

No additional vertical forces due to floor permeability were measured on capacitive force transducers.

2) Cold Mass: Once the coil is energized, the maximum bending stress appears at the middle of the long branch on opposite side of the mirror (Fig. 9) up to $25 \mathrm{Mpa}$.

3) Ribs: A maximum tensile strain excursion of $472 \mu \mathrm{m} / \mathrm{m}$ was measured at $20.5 \mathrm{kA}$ which corresponds to a tensile force of $1084 \mathrm{kN}$ considering a Young modulus of $81 \mathrm{GPa}$ at $5 \mathrm{~K}$ for Al 5083.

\section{CONCLUSIONS}

The mechanical measurements of ATLAS B0 coil model has been performed at nominal current $I=20.5 \mathrm{kA}$. External ca-

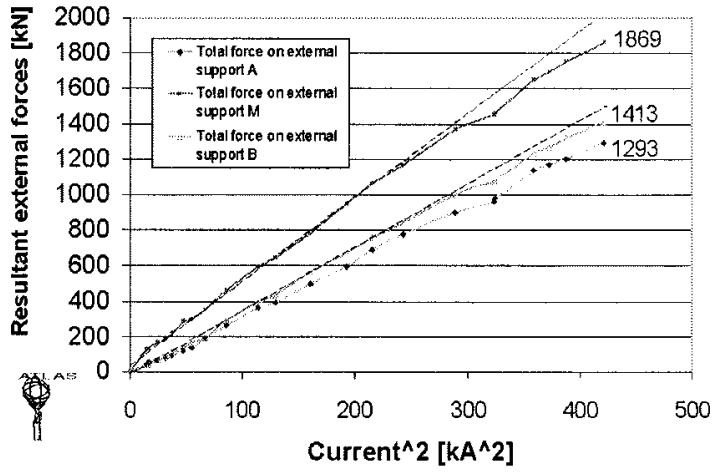

Fig. 8. Radial forces measurements on B0 coil supports with capacitive force transducers.

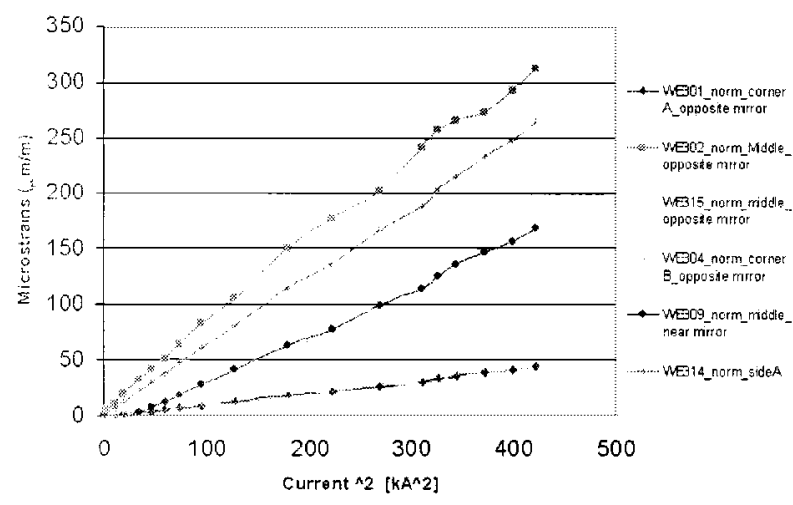

Fig. 9. Strain measurements on the cold mass during power test up to $20.5 \mathrm{kA}$.

pacitive force transducers were used in parallel with internal strain gauges system, providing also a valuable insight into mechanical behavior of forces redistribution during power tests. Those two types of instrumentation give resultant electromagnetic forces measurements to $10 \%$, and the difference may be explained with the uncertainties on material properties, strain gauges positions. All stresses in the support systems were monitored and are within safety operational limits. The successful test of the mechanical behavior of the B0 coil mechanical design is a major step to demonstrate feasibility and reliability of the ATLAS Magnet System.

\section{ACKNOWLEDGMENT}

The authors wish to thank the Atlas magnet collaboration, especially CERN/ATLAS magnet group, CEA Saclay, INFN/LASA teams for preparing some test equipment, the CERN/LHC/MMS service for capacitive force transducers instrumentation support and CERN/LHC/ECR group for operating cryogenic station.

\section{REFERENCES}

[1] H. ten Kate, "The superconducting magnet system for the ATLAS detector at CERN," IEEE Trans. on Appl. Supercond., vol. 10, Florida, USA, p. 347, 1999.

[2] P. Miele, "The ATLAS magnet test facility at CERN," IEEE Trans. Appl. Superconduct., vol. 11, Virginia Beach, USA, p. 1713, 2000. 
[3] N. Siegel, D. Tommasini, and I. Vanenkov, "Design and use of capacitive force transducers for superconducting magnet models for the LHC," in MT15 Conf.

[4] M. Sorbi, "Calculation of the forces in the coils of the Atlas Barrel Toroid and their simulation in the B0 model with magnetic mirror,", LASA/ATLAS report, Oct. 1996.
[5] - "Study of the force between B0 magnet and a magnetic mirror,", LASA/ATLAS report, Oct. 2000.

[6] C. Pes, CEA Saclay, CEA report 5C 2900 T - 6000002.

[7] F. Alessandria, F. Broggi, and M. Todero, "Mechanical characterization of the tie rods for the ATLAS B0 model coil," in MT17 Conf. 